\title{
PERFIL, PERCEPÇÃO E OPINIÃO DOS VISITANTES DO PARQUE NACIONAL DO ITATIAIA (RJ) EM PERÍODOS DE MAIOR DEMANDA
}

\author{
Marcos Paulo Oliveira ${ }^{1}$ \\ Eduardo Ferreira ${ }^{1}$ \\ Monique Ribeiro ${ }^{1}$ \\ Juliana Souza ${ }^{2}$ \\ Monika Richter ${ }^{3}$
}

\section{RESUMO}

O Parque Nacional do Itatiaia (PNI), primeira Unidade de Conservação (UC) brasileira, criada em 1937, é aberto à visitação pública desde então. Neste sentido, e considerando-se os atuais números registrados, uma das ações prioritárias é o contínuo planejamento e monitoramento deste uso público. De acordo com dados levantados pela UC, embora os meses de junho/julho sejam os de maior frequência, alguns períodos ao longo do ano recebem quantitativos significativos, atingido picos históricos de visitação como ocorreu em um único dia do ultimo feriado de carnaval. Neste contexto, o presente trabalho objetivou analisar o perfil, a percepção e opinião deste visitante tendo como estudo de caso além do feriado de Carnaval, o da Semana Santa do presente ano (2015). Para tanto foram entrevistadas 322 pessoas, utilizando-se como roteiro de questionário, o mesmo elaborado e adotado pela Unidade. Os resultados apontam que a maioria dos visitantes compreende a faixa etária entre 25 e 45 anos, possuem nível superior e são provenientes principalmente das cidades do Rio e de São Paulo. No geral, destacam como aspecto positivo o estado de conservação do PNI e como aspecto negativo, a atual condição da estrada de acesso aos principais atrativos. Conclui-se que mesmo em momentos de grande demanda de visitação, menos de $10 \%$ percebem este número como excessivo, embora em termos de manejo, um dos motivos de maior preocupação seja o gerenciamento de locais para estacionamento dos carros considerando-se que mais de $90 \%$ dos entrevistados tem como meio de transporte de acesso, veículos próprios.

Palavras chave: Uso Público, Parque Nacional do Itatiaia, Perfil de Visitantes.

\begin{abstract}
\footnotetext{
${ }^{1}$ Graduando em Turismo, Bacharelado UFRRJ/IM. E-mail: mpoliveiraufrrj@ gmail.com

${ }^{2}$ Graduando em Turismo, Licenciatura CEDERJ/ UFRRJ/IM.

${ }^{3}$ Prof. Dra. de Geografia do Departamento de Educação e Sociedade UFRRJ/IM.
}

The Itatiaia National Park (PNI), first Brazilian Protected Area, established in 1937, is open to public visits since then. In this regard and considering the current situation, one of the priorities is the continuous planning and monitoring of this public use. According to collected data, though June and July are the most demanded months in terms of public use, some holidays throughout the year receive significant quantitative, reached historical peak visitation as observed in one of the days of the carnival holyday. In this context, the present work aimed to analyze the profile, the perception and opinion of this visitor taking as a case study the Carnival and the Holy Week holidays. For thus, 322 visitors were interviewed, using a questionnaire script, the same adopted by the PNI. The results show that the majority comprises the age group between 25 and 45, have higher education and come mainly from 
Rio and Sao Paulo. Overall, they stand out as positive the PNI conservation status and as negative note, about $12 \%$, the current condition of the access road to the main attractions. We conclude that even in times of great demand for visitation, less than $10 \%$ perceive this figure as excessive, although one of the biggest reasons concern is the management of sites for car parking considering that over $90 \%$ use its own means of transport vehicles.

Keywords: Public Use, Itatiaia National Park, Visitors Profile.

\section{INTRODUÇÃO}

Segundo Brito (2007), um dos grandes problemas enfrentados pelos gestores das Unidades de Conservação, em especial as de proteção integral, é o distanciamento da população em relação aos objetivos de conservação. Neste contexto, mais do que nunca são importantes os processos de comunicação ambiental que se mostram como cruciais para chegar à população, motivá-la, aproximá-la e implicá-la na estratégia de conservação de uma área protegida. Do mesmo modo são instrumentos imprescindíveis para proteger uma UC ou outro ambiente natural dos impactos que os visitantes podem ocasionar

A diversidade de motivações, interesses e necessidades dos indivíduos que visitam os espaços naturais são enormes e estão em função de sua idade, nível de formação, lugar de procedência, tamanho do grupo com o qual se realiza a visita, frequência desta visita e outros. No entanto, a maioria, simplesmente busca alguns momentos de contato e relaxamento junto à natureza.

Guimarães (1995) afirma que uso público é o conjunto de atividades, serviços e instalações, em espaços naturais, com o fim de aproximar os visitantes a seus valores tanto naturais como culturais, de forma ordenada através de mensagens educativas, utilizando a interpretação do patrimônio como estratégia de comunicação e de valorização do ambiente natural.

Além destes, outros termos relacionados ao conceito de uso publico se destacam como participação cidadã, sensibilização ambiental, desenvolvimento turístico, etc. Termos, que podem ser considerados processos de comunicação em um sentido amplo, contudo diferem tanto nas características do público a que se dirige como no tempo retido na sua atenção.

Salienta-se que nem todos os visitantes percebem o entorno físico e social de igual forma: o que para uns pode ser uma experiência recreativa de qualidade, para outros pode resultar totalmente indesejável. A aplicação de pesquisas, diretas e pessoais, aos visitantes é o método habitualmente empregado nestes estudos. Permite realizar um monitoramento do perfil do visitante, sua percepção sobre a satisfação da visita e sua opinião sobre as distintas medidas de gestão do uso público no espaço natural. Ainda que se recomende uma periodicidade, sua elaboração pode ser programada em função dos objetivos de planejamento, assim como das necessidades de informação surgidas ante a detecção de novos perfis de visitantes potencialmente impactantes, e/ou novas atividades de uso público.

Assim, torna-se imprescindível para o planejamento e a gestão eficaz do uso público, a identificação do perfil, os parâmetros e as características que configuram estes usos. É preciso conhecer a perfil, necessidades e demandas das pessoas que visitam estes espaços. $\mathrm{O}$ 
objetivo é ordenar e regular as atividades recreativas, planejando o uso público de forma efetiva.

Como forma de pesquisa, é recomendado utilizar um modelo único de questionário, com perguntas que recolham toda a informação essencial que seja útil para a gestão de visitantes.

No atual plano de manejo do PNI (2014) constam relevantes informações sobre o uso público e as principais características da visitação. No entanto, essas informações são gerais e carecem de análises dinâmicas e mais detalhadas. De acordo com dados cedidos pela UC, embora os meses de junho/julho sejam os de maior frequência, alguns feriados e períodos do verão, especialmente quando as condições do tempo são favoráveis, com temperaturas elevadas e dias ensolarados, o PNI recebe quantitativos significativos, atingindo picos históricos de visitação como ocorreu em um único dia do ultimo feriado de carnaval, com 1.442 visitantes.

Diante do exposto, o objetivo principal deste trabalho é identificar o perfil, percepção e opinião dos visitantes do PNI, considerando períodos de maior demanda e tendo como estudo de caso os feriados de carnaval e semana santa de 2015. Objetivou-se também avaliar de maneira expedita, possíveis alterações e impactos da visitação pública nos principais atrativos da Parte Baixa do PNI.

\section{METODOLOGIA}

\section{Área de Estudo}

O PNI localiza-se na Serra da Mantiqueira, abrangendo parte dos municípios de Itatiaia e Resende, no estado do Rio de Janeiro e de Itamonte e Bocaina de Minas, no estado de Minas Gerais. De acordo com o Plano de Manejo (ICMBio, 2013), seu relevo é montanhoso e escarpado, com elevações que variam entre $540 \mathrm{~m}$, no extremo sul do PNI até $2.791 \mathrm{~m}$ no Pico das Agulhas Negras, sendo que predominam altitudes em torno de $2.000 \mathrm{~m}$, e declividades entre 30 a $47 \%$. Tais características corroboraram para o bom estado de conservação geral, sustentando comunidades ricas de flora e fauna, representativas da biodiversidade regional e com elementos raros, ameaçados e endêmicos.

\section{Materiais e Métodos}

A presente pesquisa configura-se como de caráter exploratório por meio de pesquisa bibliográfica e de incursões à campo. Dentre as fontes de consulta destacam-se o plano de manejo do PNI, encartes 3 e 4, publicado em 2014 (o plano foi elaborado em 2013 mas oficializado em 2014) e a referência Diretrizes para Visitação em Unidades de Conservação, do MMA (2007).

Em uma segunda etapa, realizou-se trabalho de campo em dois períodos específicos: Carnaval e Semana Santa, por serem indicados como os de maior visitação ao longo do ano. Para a entrevista junto aos visitantes, adotou-se o modelo de questionário elaborado e utilizada pela UC de maneira a se permitir comparativos com outros estudos. 
O questionário, conforme ressaltado, é estruturado em eixos buscando identificar o perfil do visitante, características da visita, opinião, expectativas e, ao final, sugestões de melhorias.

Ao todo, foram 202 entrevistados entre os dias 13 a 18 de fevereiro (Carnaval) de 2015, e 120 entrevistados nos dias 03 e 04 de abril (Período de Páscoa) do mesmo ano, totalizando 322 questionários aplicados no período objeto de estudo.

Também foram realizadas observações participantes dos atrativos mais visitados na Parte Baixa e entrevistas livres com alguns funcionários do PNI sobre questões identificadas em campo, como significativo número de visitantes, o excesso de carros e a percepção destes frente aos possíveis impactos desta visitação.

Por fim, os dados foram sistematizados, quantificados e analisados considerando-se as observações e a percepção dos autores em campo, bem como comparativamente com resultados alcançados por ocasião da elaboração do Plano de Manejo (ICMBio, 2014).

\section{RESULTADOS}

Conforme já salientado, das 322 entrevistas realizadas, 62,73\% foram no Carnaval e o restante no feriado de Semana Santa.

\section{Perfil dos visitantes}

Em termos de perfil do visitante quanto à origem (Figura 1) observou-se que 21,53\% dos entrevistados são da região do entorno (Vale do Paraíba), sendo o fluxo maior proveniente dos grandes centros urbanos como Rio de Janeiro $(35,46 \%)$ e São Paulo $(11,54 \%$.). Neste aspecto os resultados se assemelham aos citados no plano de manejo.

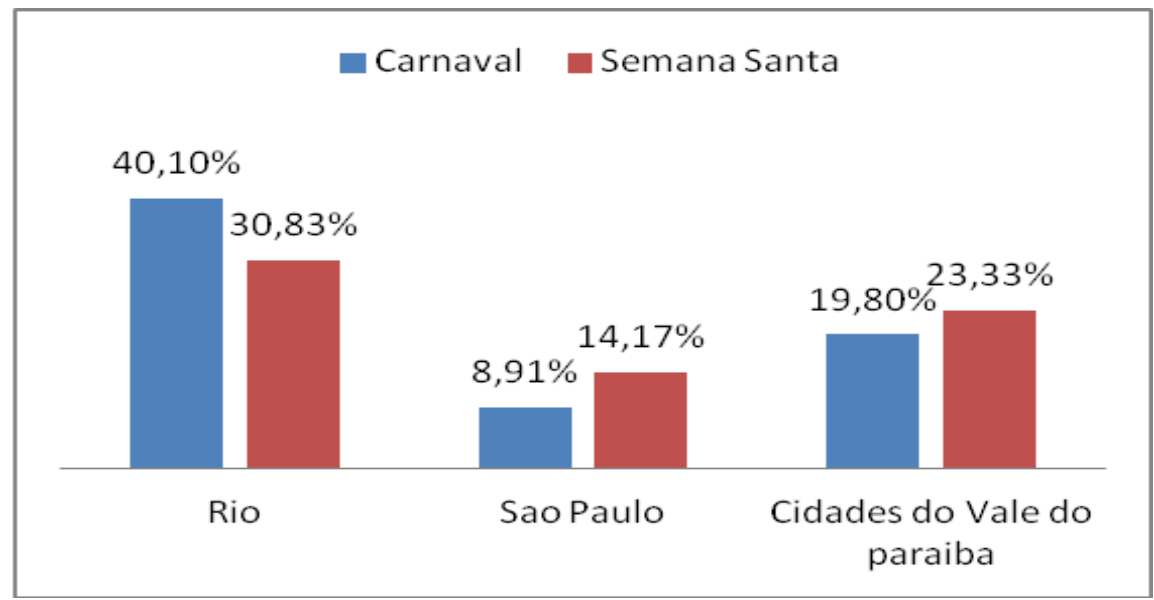

Figura 1. Origem dos visitantes do PNI no período de Carnaval e Páscoa de 2015.

Em relação ao gênero, pôde-se observar que a maioria dos visitantes, cerca de 56,5\%, é do sexo masculino. 
Já a faixa etária predominante variou entre os feriados: no Carnaval predominou a faixa entre 46 e 59 anos, com $32,67 \%$ e na semana santa predominou a faixa entre $35-45$ com 43,33\% (Figura 2). No entanto, é preciso considerar que as crianças não foram entrevistadas e que estavam presentes especialmente na Parte Baixa do Parque, acompanhados das respectivas famílias.

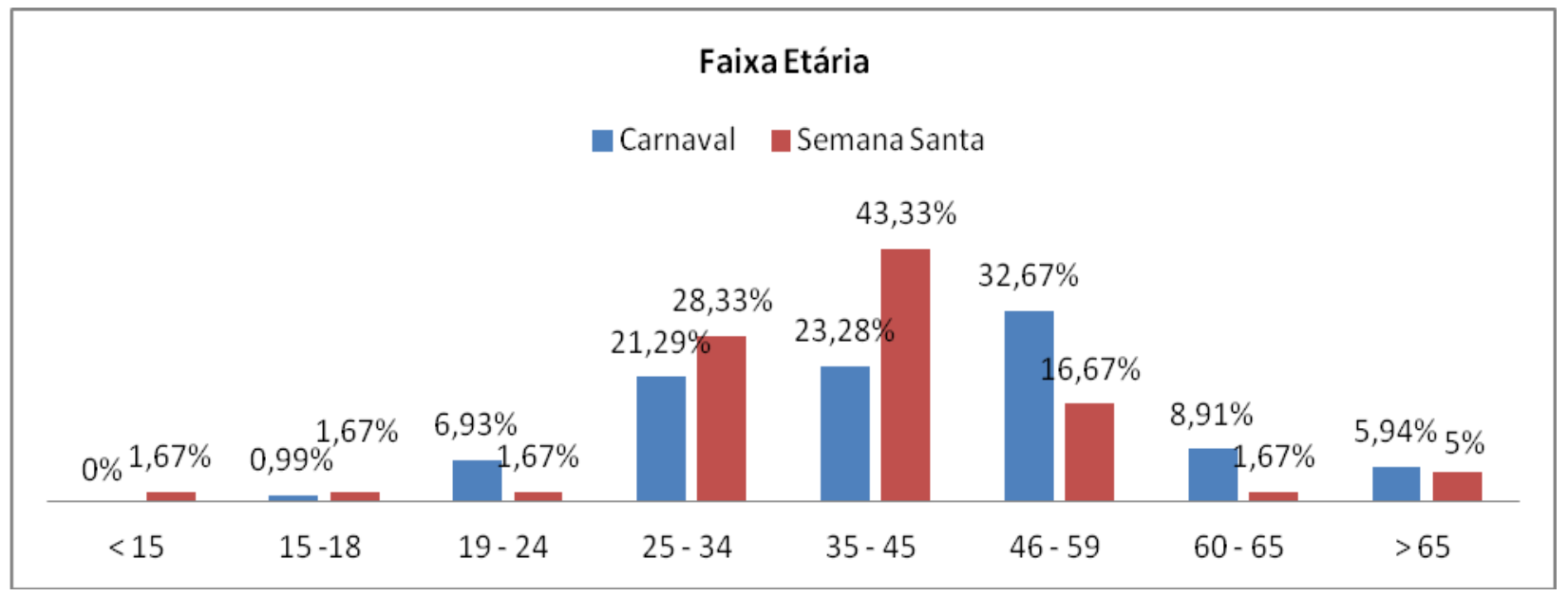

Figura 2 - Faixa etária dos Visitantes do PNI

Quanto ao grau de escolaridade, destaca-se o nível superior, com 50\% (Figura 3). Este acrescido dos que possuem pós-graduação, chega-se a $69 \%$ dos entrevistados. Já para o quesito renda, verificou-se que a maioria sentiu-se desconfortável em fornecer tal dado, atingindo $61 \%$ dos consultados.

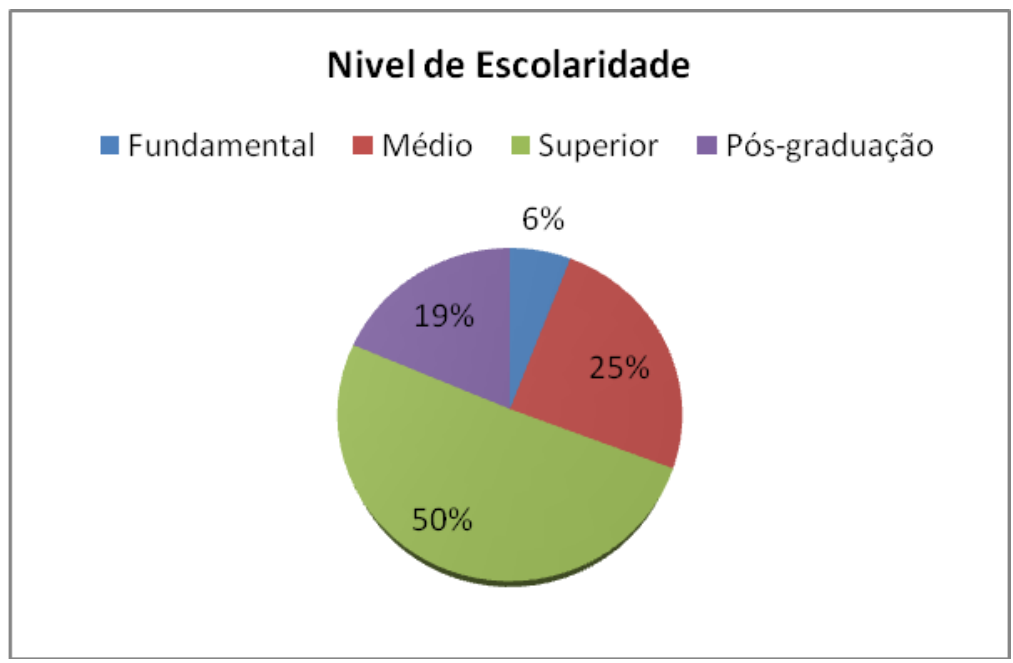

Figura 3- Nível de Escolaridade dos Visitantes do PNI 


\section{Percepção do Visitante}

Em termos de percepção ambiental, quando consultados sobre a principal função de um Parque Nacional, cerca de 70\% respondeu ser a proteção dos ecossistemas, acrescido de local para realização de estudos e pesquisa, demonstrando conhecimento sobre os objetivos desta categoria de UC. Somente $30 \%$ responderam ser o lazer (Figura 4).

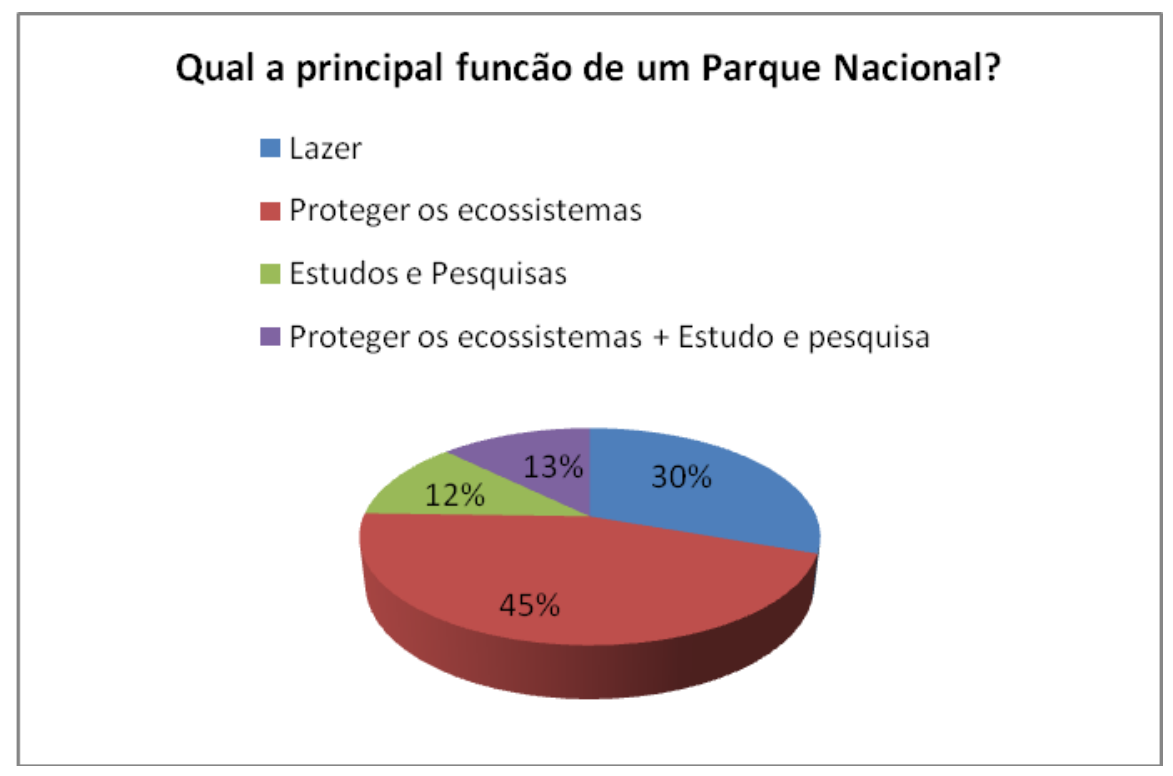

Figura 4 - Qual a Principal Função de um Parque Nacional na percepção dos visitantes do PNI

\section{Características da Visitação}

Uma das condicionantes que chamou a atenção relacionada aos entrevistados é o fato de que mais da metade estava visitando o PNI pela primeira vez em ambos os feriados (Figura 5).

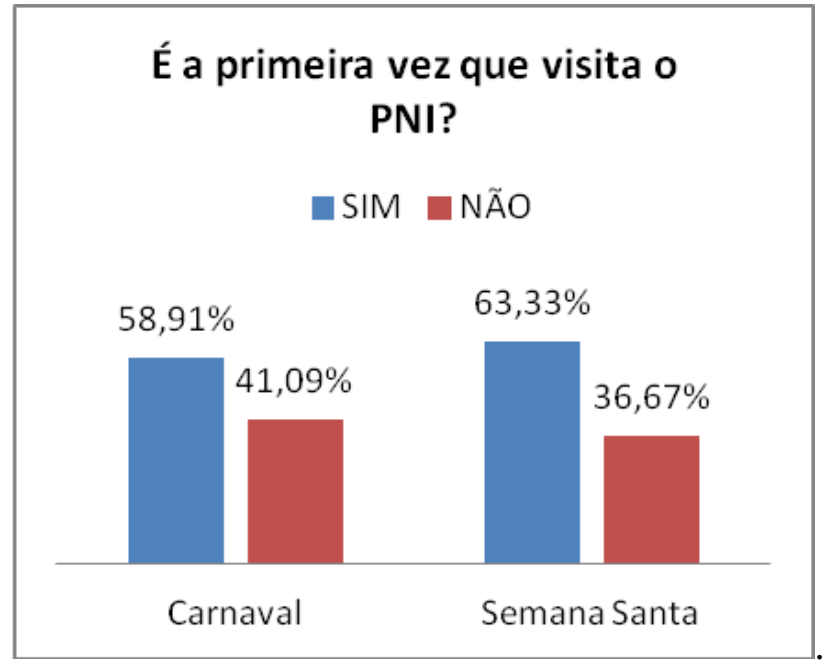

Figura 5 - Se é a primeira vez que o entrevistado visita o PNI 
O resultado indica a que embora a UC seja localizada no eixo Rio - São Paulo e ser de fácil acesso, muitos podem não estar retornando, apesar de 99\% afirmar que gostaria de visitá-lo novamente. Neste sentido para melhor analisar esta questão, algumas condicionantes devem ser investigadas tais como: tamanho da amostra, frequência da amostra, período histórico a que se refere oscilação do número de visitantes no período, etc.

Quanto ao meio de transporte, mais de $90 \%$ acessam a UC com veículo próprio (Figura 6). Também foram observados ônibus de excursão e a utilização ônibus urbano. Se considerarmos que boa parte dos visitantes está acompanhada de suas famílias (Figura 7), pode-se estimar que em momentos de maior frequência, cerca de 250 carros circulam na área de uma única vez. Este quantitativo estimado representa muito mais do que a capacidade de suporte de estacionamento e de acesso, configurando-se como uma das questões prioritárias relacionadas ao uso público na Parte Baixa.

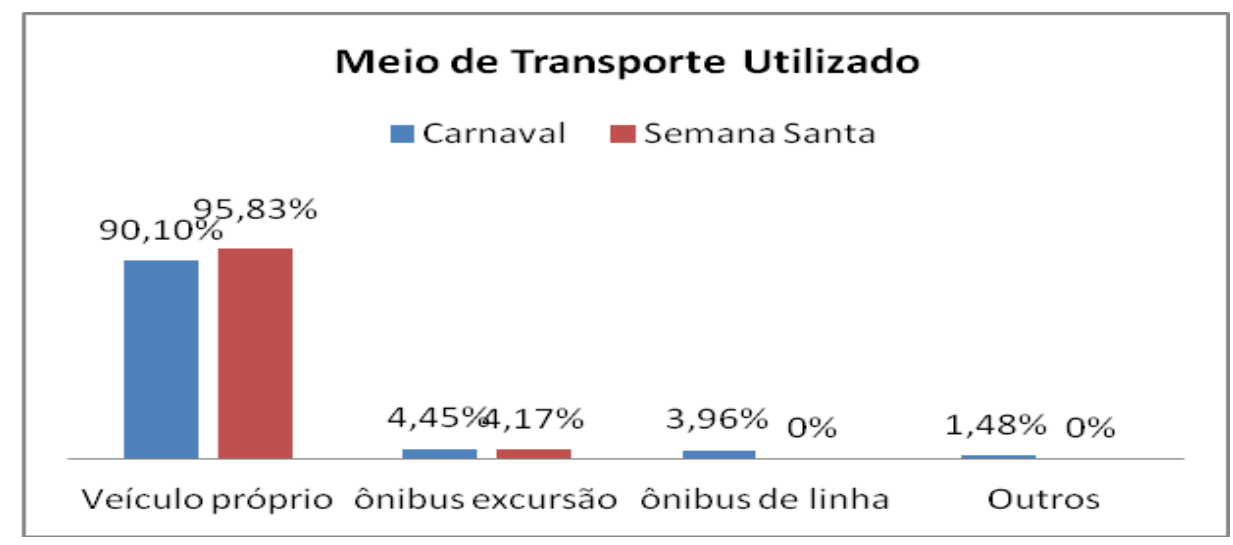

Figura 6 - Meio de Transporte utilizado para acessar o PNI

No período estudado não foram observados conflitos em relação ao quantitativo de carros, porém, segundo o Plano de Manejo (Encarte 3), próximo a Ponte do Maromba, é comum acontecerem brigas entre motoristas em meio aos congestionamentos.

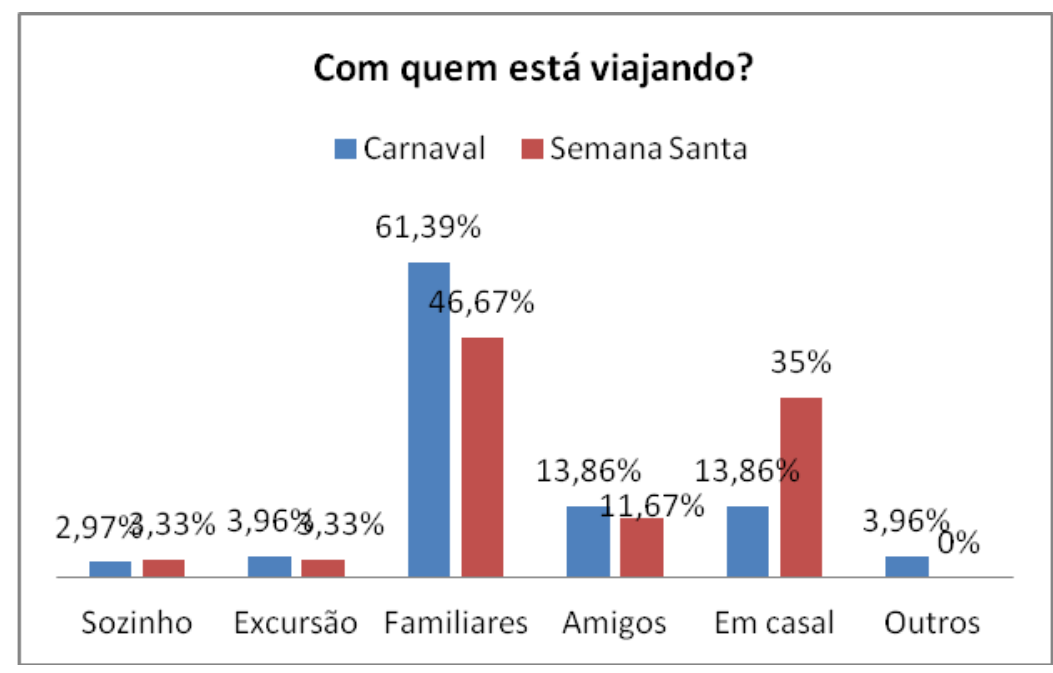

Figura 7 - Se o visitante foi acompanhado ao PNI 
As atividades de lazer ainda se configuram como a principal motivação à visitação, observando-se, porém cerca de $20 \%$ de diferença entre as motivações do público do Carnaval e o do feriado de Páscoa. Neste caso, foi assinalado também um razoável interesse em se conhecer aspectos da natureza (Figura 8).

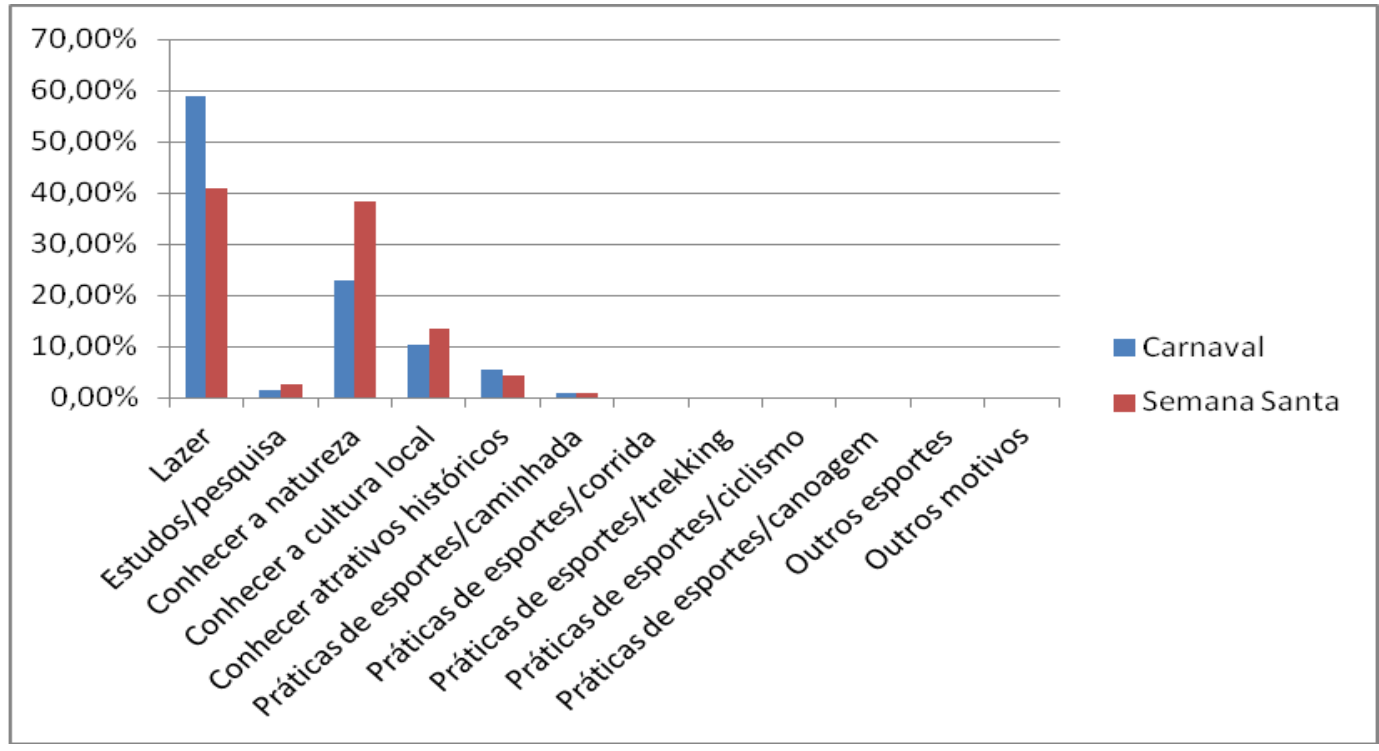

Figura 8 - Motivo da Visita

Também foram identificados, embora de maneira menos expressiva, o interesse pela cultura local, indicando o potencial para ações voltadas à interpretação socioambiental.

\section{Opinião sobre o Parque}

Muitos entrevistados alegaram ter vivenciado uma experiência única apreciando o Parque em diversos aspectos (Figura 9). Os dados obtidos reforçam a fala, indicados pelos elevados percentuais de avaliação geral da UC como muito boa a excelente, o fato de muitos terem interesse em conhecer outras áreas do parque, além de quase todos terem a intenção em retornar ao parque (99\%).

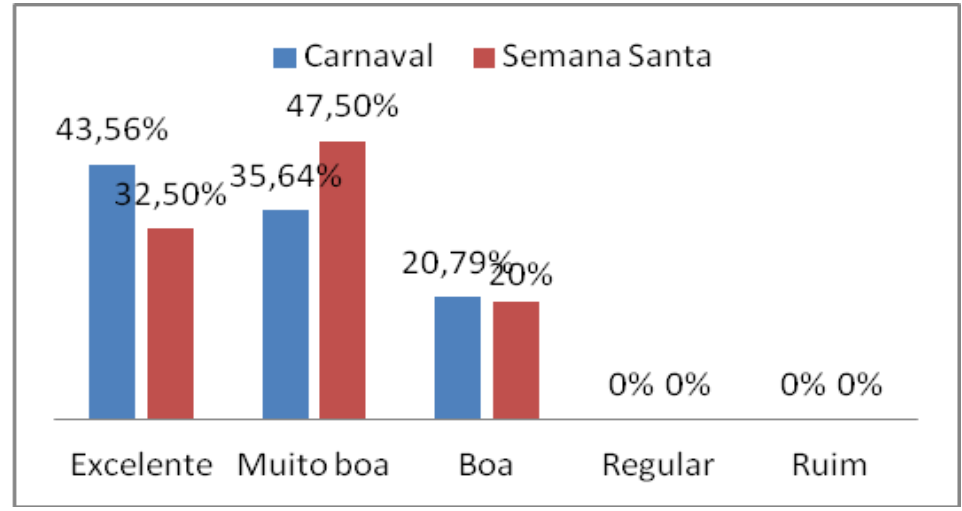

Figura 9 - Avaliação Geral sobre a Visita ao PNI 
Em relação à percepção do usuário frente ao elevado número de visitantes nos atrativos (Figura 10), chama a atenção que, embora tenham sinalizado que consideram a lotação razoável ou que o Parque esteja cheio de pessoas, poucos disseram ser excessiva a presença de visitantes, demonstrando que a alta frequência não interfere na experiência e vivenciada no local.

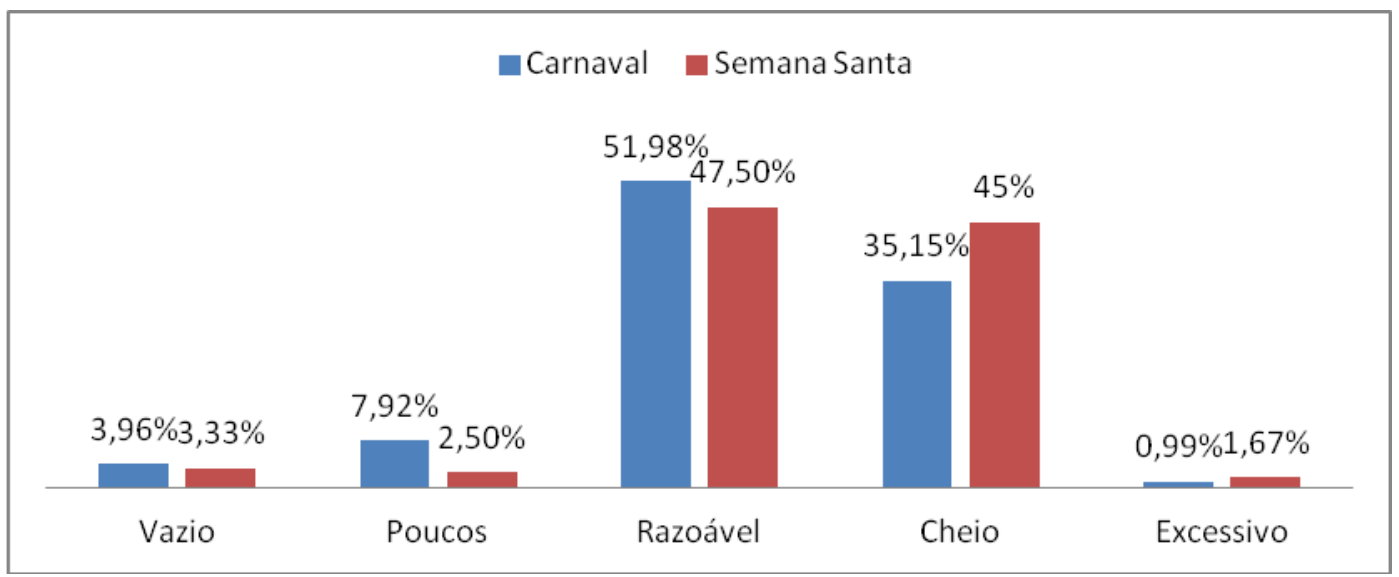

Figura 10 - Percepção sobre o número de turistas nos atrativos

Quanto à conservação e manutenção dos atrativos, as respostas também apresentaram caráter positivo como limpeza, área bem conservada, organização e sinalização.

Finalizando as investigações, os visitantes foram consultados sobre os aspectos positivos (Figura 11), sendo destacadas as cachoeiras e a natureza.

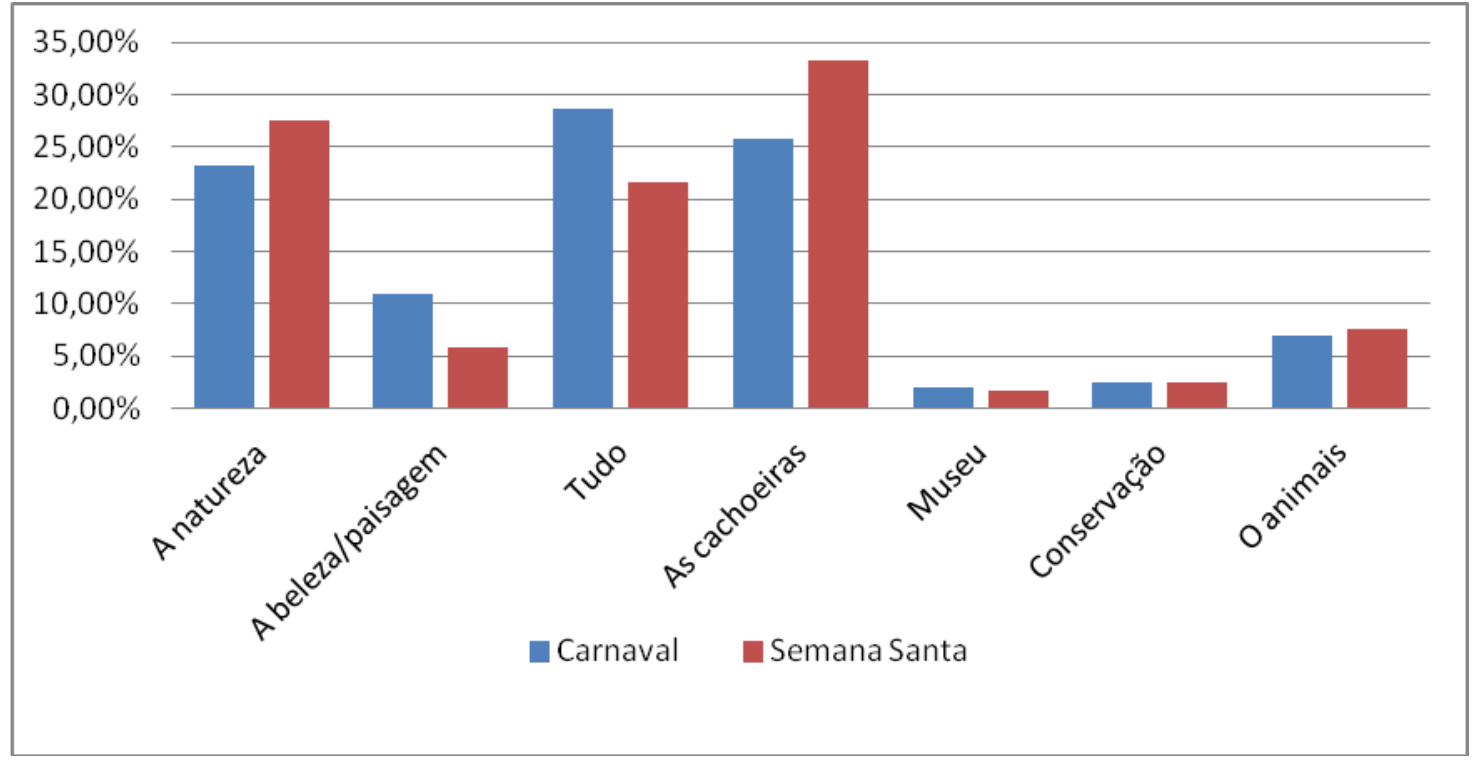

Figura 11- Aspectos Positivos na visitação do PNI 
Como aspectos negativos (Figura 12), embora tenham sido menos de 20\%, foram apontados dados sobre a condição da estrada de acesso aos atrativos, fato também identificado por ocasião dos levantamentos realizados para o plano de manejo.

Considerando que o visitante paga uma taxa ao entrar na UC e desconhece que a estrada é de gestão de outro órgão, isso poderia ser informado além do destino da taxa que serve prioritariamente às ações de defesa da natureza.

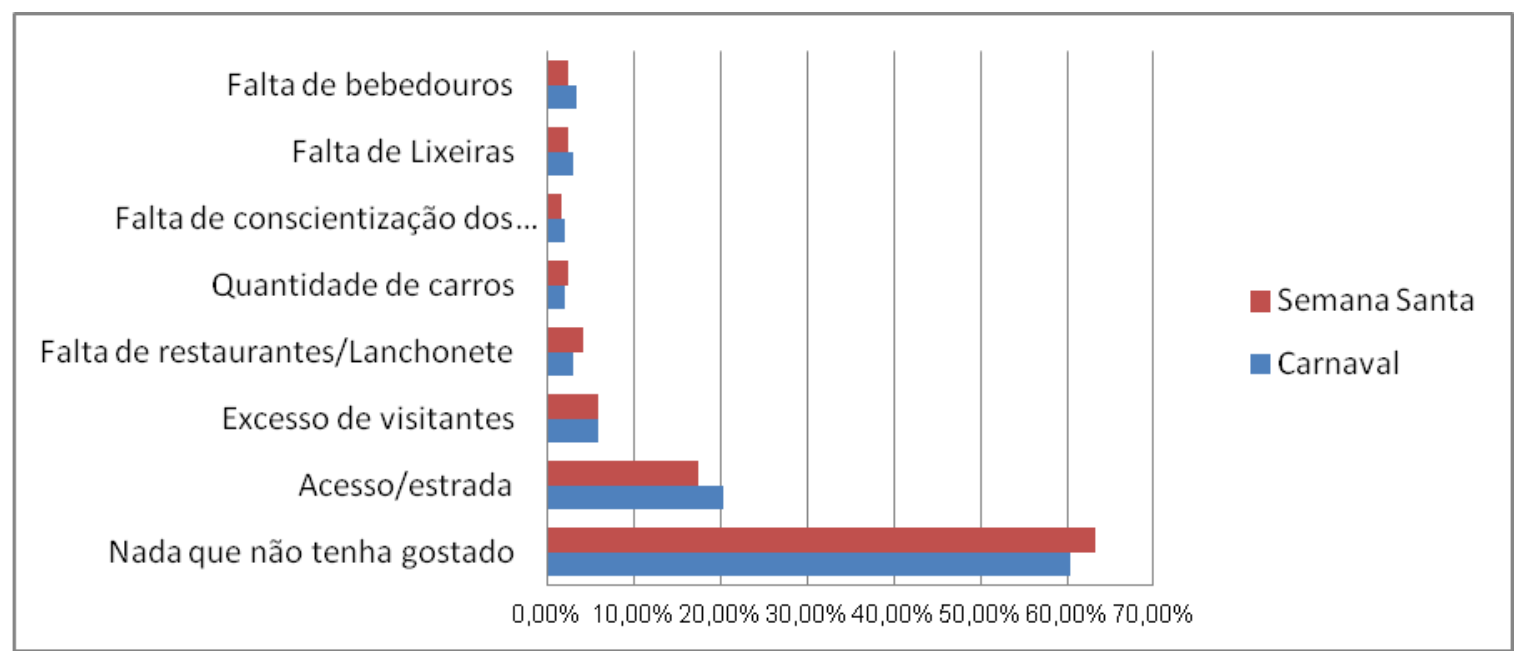

Figura 12 - Pontos Negativos sobre a Visita

Ou seja, mesmo que haja algumas reclamações, o público em sua maioria busca obter o melhor que o Parque oferta. Segundo um dos entrevistados questões como "condição da estrada e falta de lanchonetes podem ser um problema, entretanto, a beleza natural e as experiências que o PNI oferece, recompensam".

\section{CONCLUSÕES}

Com os resultados desta pesquisa, conclui-se que o PNI oferece oportunidades de recreação e de interpretação ambiental aos visitantes que buscam maior contato com a natureza. Através dos atrativos, o visitante pode observar aspectos diferentes de fisionomias e paisagens, as quais proporcionam o contato direto com experiências únicas, como observação da fauna local e seu comportamento, contemplação da paisagem com seus aspectos singulares, lazer junto às cachoeiras, dentre outros.

Em relação ao perfil do visitante, a maioria dos visitantes compreende a faixa etária entre 25 e 45 anos, possuem nível superior e são provenientes principalmente das cidades do Rio e de São Paulo. No geral, destacam como aspecto positivo o estado de conservação do PNI e como aspecto negativo, a atual condição da estrada de acesso aos principais atrativos. Conclui-se que mesmo, em momentos de grande demanda de visitação, menos de $10 \%$ percebem este número como excessivo, embora em termos de manejo, um dos motivos de maior preocupação seja o gerenciamento de locais para estacionamento dos carros 
considerando-se que mais de $90 \%$ dos entrevistados tem como meio de transporte de acesso, veículos próprios.

Com base nesse estudo, é possível não só melhor orientar sobre as necessidades de mudança, aprofundando aspectos voltados a interpretação dos patrimônios ambiental e cultural envolvidos, mas também despertando a conscientização ambiental.

\section{AGRADECIMENTOS}

Aos funcionários do Parque Nacional do Itatiaia pelas informações cedidas e pelo apoio logístico nas atividades de campo em especial ao Leonardo Candido, Marcelo Motta e ao Gustavo Tomzynski.

\section{REFERÊNCIAS BIBLIOGRÁFICAS}

MINISTÉRIO DO MEIO AMBIENTE. Diretrizes para Visitação em Unidades de Conservação. 72.p. Brasília, 2007.

INSTITUTO CHICO MENDES DE CONSERVAÇÃO DA BIODIVERSIDADE - ICMBio. Plano de Manejo Parque Nacional do Itatiaia. Encarte 4, 77p. Brasília, 2013. Disponível em:

http://www.icmbio.gov.br/portal/images/stories/docs-planos-demanejo/pmparnaitatiaiaenc3.pdf. Acesso em: 30 abr. 2014.

INSTITUTO CHICO MENDES DE CONSERVAÇÃO DA BIODIVERSIDADE - ICMBio. Plano de Manejo Parque Nacional do Itatiaia. Encarte 4, 77p. Brasília, 2013. Disponível em:<http://www.icmbio.gov.br/portal/images/stories/docs-planos-demanejo/pm_parna_itatiaia_enc4.pdf $>$. Acesso em: 30 abr. 2014.

BRITO, F. E. M. Ecos contraditórios do turismo. Salvador: Edufba, 2007. 197p

GUIMARÃES, M. A Dimensão ambiental na educação. 2. ed Campinas, São Paulo: Papirus. 1995. 